Technological University Dublin

DÜBLIN

ARROW@TU Dublin

Articles

School of Biological Sciences

2017

\title{
PCR-ribotype distribution of Clostridium difficile in Irish pigs
}

\author{
Katharina Stein \\ University College Dublin, k.stein@svuh.ie \\ Sarah Egan \\ Technological University Dublin, sarah.egan@tudublin.ie \\ Helen Lynch \\ University College Dublin
}

See next page for additional authors

Follow this and additional works at: https://arrow.tudublin.ie/scschbioart

Part of the Animal Diseases Commons

\section{Recommended Citation}

Stein K, Egan S, Lynch H, Harmanus C, Kyne L, Herra C, McDermott S, Kuijper E, Fitzpatrick F, FitzGerald S, Fenelon L, Drudy D. PCR-ribotype distribution of Clostridium difficile in Irish pigs. Anaerobe. 2017 Dec;48:237-241. doi: 10.1016/j.anaerobe.2017.10.004. Epub 2017 Oct 9. PMID: 29024758.

This Article is brought to you for free and open access by the School of Biological Sciences at ARROW@TU Dublin. It has been accepted for inclusion in Articles by an authorized administrator of ARROW@TU Dublin. For more information, please contact arrow.admin@tudublin.ie, aisling.coyne@tudublin.ie,gerard.connolly@tudublin.ie.

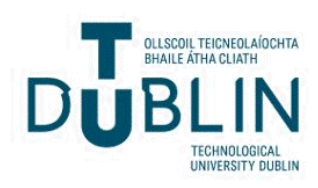




\section{Authors}

Katharina Stein, Sarah Egan, Helen Lynch, Celine Harmanus, Lorraine Kyne, Celine Herra, Sinead

McDermott, Ed Kuijper, Fidelma Fitzpatrick, Susan FitzGerald, Lynda Fenelon, and Denise Drudy

This article is available at ARROW@TU Dublin: https://arrow.tudublin.ie/scschbioart/318 
C.difficile (including epidemiology)

\title{
PCR-ribotype distribution of Clostridium difficile in Irish pigs
}

\author{
Katharina Stein a, b, *, Sarah Egan c, Helen Lynch a , Céline Harmanus ${ }^{\text {d }}$, Lorraine Kyne a, e, \\ Celine Herra ${ }^{c}$, Sinead McDermott ${ }^{b}$, Ed Kuijper ${ }^{d}$, Fidelma Fitzpatrick ${ }^{\text {f, g, }}$ \\ Susan FitzGerald ${ }^{\mathrm{a}, \mathrm{b}}$, Lynda Fenelon ${ }^{\mathrm{a}, \mathrm{b}}$, Denise Drudy ${ }^{\mathrm{c}}$ \\ a University College Dublin, Ireland \\ b St. Vincent's University Hospital, Dublin, Ireland \\ ${ }^{\text {c } D I T ~ D u b l i n ~ I n s t i t u t e ~ o f ~ T e c h n o l o g y, ~ I r e l a n d ~}$ \\ d Leiden University Medical Centre, The Netherlands \\ e Mater Misericordiae University Hospital, Dublin, Ireland \\ ${ }^{\mathrm{f}}$ Beaumont Hospital Dublin, Ireland \\ ${ }^{g}$ Royal College of Surgeons in Ireland, Dublin, Ireland
}

\section{A R T I C L E I N F O}

\section{Article history:}

Received 17 August 2016

Received in revised form 25 September 2017

Accepted 7 October 2017

Available online 9 October 2017

Handling Editor: Maja Rupnik

\section{Keywords:}

Clostridium difficile

Irish pigs

Prevalence

PCR-Ribotype distribution

PCR-Ribotype 078

Pig farm

Porcine strains

\begin{abstract}
A B S T R A C T
Clostridium difficile is an important enteric pathogen in humans causing infections in the healthcare environment and the community. Carriage of $C$. difficile and $C$. difficile-related enterocolitis has been reported in piglets worldwide. The aim of this study was to investigate the rates of $C$. difficile isolation from pigs in Ireland. Faecal samples from piglet litters and sows were collected from six farms in 2015. The sows were non-diarrhoeal at the time of sampling. The diarrhoeal status of the piglets was unknown. C. difficile was isolated from 34/44 (77\%) of piglet litter samples and from 33/156 (21\%) of sow samples. The isolation rate in sows varied from 3 to $39 \%$ and in piglet litters from 72 to $86 \%$ depending on farm location. Toxin A and toxin B were present in 99\% (66/67) of isolates; and binary toxin in 85\% (57/67). Only PCR-ribotypes 078 (88\%) and $193(12 \%)$ were identified in piglets. Seven PCR-ribotypes were detected in sow C. difficile isolates: PCR-ribotypes 078 (67\%), 050 (12\%), 014/020 (6\%), 015 (6\%), 029 (3\%), 035 (3\%) and 193 (3\%). This study shows that toxigenic C. difficile strains such as PCR-ribotype 078 can be commonly isolated from pigs at different geographical locations in Ireland. Since PCR-ribotype 078 is frequently found in humans in Ireland, this highlights the potential for interspecies transmission.
\end{abstract}

() 2017 Elsevier Ltd. All rights reserved.

\section{Importance}

This is the first study that has investigated $C$. difficile isolation rates, PCR-ribotype prevalence and toxin profiles of $C$. difficile isolates in sows and piglets on conventional pig farms in Ireland. The incidence of community-associated C. difficile PCR-ribotype 078 infections is increasing in Ireland. One possible source of $C$. difficile in the community might be animals. This study highlights the isolation of $C$. difficile PCR-ribotype 078 from Irish livestock and the potential for interspecies transmission.

\footnotetext{
* Corresponding author. Present address: St. Vincent's University Hospital Dublin, Microbiology Department, Elm Park, Dublin 4, Ireland.

E-mail address: k.stein@svuh.ie (K. Stein).
}

\section{Introduction}

Clostridium difficile is a common cause of antibiotic-associated diarrhoea and colitis in humans and has historically been associated with infections in the healthcare environment. In the last decade, the number of outbreaks of severe $C$. difficile infection (CDI) has increased worldwide, with infection associated with a high mortality rate [1]. CDI is not only a financial burden for healthcare facilities, it has become a global health challenge [2]. The increased incidence of severe CDI has been attributed to the emergence of previously rare and more virulent $C$. difficile strain types (PCRribotype 027 and 078). C. difficile produces several toxins that contribute to its virulence. The majority of strains produce toxin $A$ ( TcdA) and toxin $B(T c d B)$. Although a minority of ribotypes produce binary toxin, $C$. difficile strains producing this toxin have been isolated more frequently in recent years. As yet the role of this binary toxin in infection and its contribution to virulence remain unclear 
[3].

The high prevalence of $C$. difficile in both livestock and companion animals has recently emerged as a potential reservoir of C. difficile outside the human host and is linked to public health issues [4]. Many European studies have investigated the prevalence of $C$. difficile in animals including cattle, poultry, sheep, horses and pigs and several PCR-ribotypes have been documented in these different animal host species [4-7]. Predominant C. difficile PCRribotypes vary with animal species and geographical location. However, a distinct clonal lineage of $C$. difficile PCR-ribotype 078 predominates in pigs and cattle in the Northern Hemisphere $[4,8,9]$. Similar PCR-ribotype 078 clones may be found in both human and animal species, highlighting the potential for zoonotic transmission following direct exposure to animal reservoirs [10].

Although various animal species have reported $C$. diffcile carriage, consistently high isolation rates have been found in young healthy piglets [11]. Carriage rates of $74 \%$ have been reported in healthy 2 day old piglets in one longitudinal investigation. Other studies have documented rates of $78 \%$ carriage in piglet samples $[12,13]$. Even though isolation rates from adult pigs are lower, reports of up to $40 \%$ carriage in sows have been reported.

The pig industry in Ireland is the third most important agricultural sector after beef and milk production [14]. The number of pig farms in Ireland compared with other European countries is low, but the size of Irish pig herds is much larger [14]. Despite growing concerns regarding the prevalence of CDI in swine herds in Europe and the potential for interspecies transmission, no studies have been conducted to investigate faecal carriage and shedding rates of $C$. difficile in Irish pig farms.

Since 2000, C. difficile has been documented as a major cause of enteric disease in piglets. The onset of CDI in piglets starts shortly after birth; within the first seven days of life piglets develop pasty, watery diarrhoea and some undergo periods of constipation [15]. Typholocolitis associated with $C$. difficile has recently been reported in three Irish piglets on a commercial pig farm [16].

The aim of this study was to determine the isolation rates of C. difficile from piglets and sows from geographically distinct Irish farms. Additionally, these porcine $C$. difficile strains were characterised by investigating the genes encoding toxin A, toxin B and binary toxin and the PCR-ribotype distribution of these Irish porcine $C$. difficile strains was determined.

\section{Materials and methods}

\subsection{Farm selection and sampling}

Porcine faecal samples were collected from pig farms in six geographically different locations in Ireland between December 2014 and June 2015, two in the north east of the country (N1, N2), two in the midlands (M1, M2) and two in the south of the country (S1, S2) as part of a Salmonella spp. surveillance program in Irish pigs. The farms were selected as the animals from these farms had a $>60 \%$ positivity rate for Salmonella spp. on carcasses at the slaughter house, suggesting that infection control practices may not have been ideal on those farms. Herd sizes on the different farms ranged between 90 and 700 sows ( $11=90$ sows, $\mathrm{M} 2=180$ sows, $\mathrm{S} 1=300$ sows, $\mathrm{N} 2=300$ sows, $\mathrm{S} 2=650$ sows and $\mathrm{M} 1=700$ sows).

Sow samples were collected from all six locations whilst piglet litter samples were only collected from two farms in the south of the country and one in the midlands region. Sow samples were either taken from the rectum through digital rectum stimulation or from freshly voided faeces. Gloves were changed in between sows to avoid cross-contamination. A quantity of approximately $25 \mathrm{~g}$ of faeces were collected from each sow. A second faeces sample was collected from 15 sows between 1 and 3 months after the first faeces sample was taken. Sow samples were collected between December 2014 and June 2015 and samples were stored at $-20{ }^{\circ} \mathrm{C}$ before processing.

Samples from piglet litters were collected as a pooled sample from piglets belonging to the same litter. A fresh pooled piglet faecal sample ( $10 \mathrm{~g}$ ) was collected from the dejection area, choosing recent excretions and avoiding those in contact with the farrowing pen floor. This procedure ensured that sow faecal material did not contaminate the piglet faeces. All piglet faecal samples were collected in June 2015. Due to limitations associated with small sample volumes collected, piglets' faeces were diluted 1:10 in buffered peptone water and stored at $4{ }^{\circ} \mathrm{C}$ before processing.

The age of the piglets at sample collection was categorised as either between 0 and 7 days $(n=12)$ or between 14 and 28 days $(n=32)$ at times of sampling. The age of the sows was estimated in accordance with the parity cycle i.e. the number of litters farrowed. One parity cycle from insemination of sows to the end of farrowing takes approximately six months. Sows were allocated to parity 1 $(\mathrm{n}=36)$, parity $2(\mathrm{n}=17)$, parity $3(\mathrm{n}=12)$, parity $4(\mathrm{n}=13)$, parity $5(n=1)$, parity $6(n=4)$ or unknown $(n=73)$. Of the 73 sow samples whose parity was not documented, 30 (41\%) of these sows were at least 12 months of age, as they had previously produced piglet litters. The gestational status of sows varied and samples were taken during service (within one week after artificial insemination of sows) $(\mathrm{n}=72)$, gestation $(\mathrm{n}=77)$ and farrowing (one month after giving birth) $(\mathrm{n}=7)$. Information on diarrhoeal status and the parity of animals was documented where available. A link between mother and offspring was only known for eight sows and piglet litters.

\subsection{Culture, isolation and identification of $C$. difficile}

An enrichment step in cycloserine-cefoxitin fructose broth supplemented with $7 \%$ horse blood and $0.1 \%$ taurocholate was performed (Oxoid CM0601, SR0096) [17,18]. Approximately $1 \mathrm{~g}$ of sow faeces or $1 \mathrm{ml}$ of buffered peptone water with piglet faeces was inoculated into $9 \mathrm{ml}$ of pre-reduced enrichment broth. The enrichment broths were incubated under anaerobic conditions at $37{ }^{\circ} \mathrm{C}$ for seven days. Following incubation an alcohol shock was carried out for $1 \mathrm{~h}$ at room temperature using $1 \mathrm{ml}$ of $70 \%$ methanol and $1 \mathrm{ml}$ faecal enrichment broth. Samples were briefly mixed and inoculated onto $C$. difficile selective media using a $5 \mu$ inoculation loop (LIP, Fannin Group) and incubated anaerobically for 24-48 hrs at $37^{\circ} \mathrm{C}$. Presumptive colonies were identified by colonial morphology and characteristic odour. Isolate identification was confirmed using MALDI-TOF mass spectrometry after preparing pure cultures of a single colony per sample on blood agar plates.

\subsection{DNA isolation, multiplex-PCR and PCR-Ribotyping}

Total bacterial DNA was extracted from pure cultures of all confirmed $C$. difficile isolates using a commercial extraction kit provided by Qiagen (QIAamp DNA Blood Mini Kit). To confirm the identification of $C$. difficile isolates and characterise their enteropathogenic properties a 5-plex PCR was utilised according to Persson et al. [19] to detect the presence of the genes encoding for TcdA, TcdB, CDT (binary toxin), glutamate dehydrogenase (GluD) and 16SrDNA. Agarose-based PCR-ribotyping was performed according to Bidet et al. [20]. PCR-ribotypes were assigned using the BioNumerics software by comparing fingerprint patterns of representative PCR-ribotypes obtained from the Leiden University Medical Centre Library, the Netherlands. 


\section{Results}

\subsection{Farm demographics and C. difficile isolation rates}

A total of 200 faecal samples were collected from 44 piglet litters and 156 sows. The $C$. difficile recovery rate varied between piglet litters and sows. C. difficile was isolated from 77\% (34/44) of piglet litter samples and in $21 \%$ (33/156) of sow samples. The $C$. difficile isolation rate in piglet litter samples varied from 72 to $86 \%$ and in sow samples from 3 to $39 \%$ between farms. The highest $C$. difficile isolation rate in piglet litters was $86 \%(12 / 14)$ on farm S2, followed by farms M1 $(75 \%, 9 / 12)$ and S1 $(72 \%, 13 / 18)$ (Table 1$)$. The greatest isolation rate in sow samples was found on farm N1 with 39\% (17/ 44) followed by farm M2 with $23 \%$ (10/43), farm N2 with $14 \%(2 / 14)$, farm S1 with $8 \%(2 / 25)$ and farm S2 with $4 \%(1 / 28)$. The isolation rate of $C$. difficile varied between piglet litters of different ages. C. difficile was isolated from $58 \%$ (7/12) of litters with piglets aged 0-7 days and from $84 \%$ (27/32) of $14-28$ day old piglets. C. difficile isolation rates were lower in sows and varied according to different gestational status. Samples taken during service showed a higher isolation rate of $40 \%$ (29/72) compared with isolation rates of only $14 \%(1 / 7)$ and $4 \%$ (3/77) which were found during stages of farrowing and gestation, respectively. $C$. difficile was recovered from $17 \%(6 / 36)$ of parity 1 sows, in $17 \%$ (2/17) of parity 2 sows and in $34 \%$ $(25 / 73)$ of sows with unknown parity.

\subsection{Strain characterisation and PCR-ribotype distribution}

Toxin genes encoding toxin $\mathrm{A}(\operatorname{Tcd} \mathrm{A})$ and toxin $\mathrm{B}(\mathrm{TcdB})$ were found in 99\% (66/67) of all C. difficile isolates. The gene encoding binary toxin (CDT) was detected in $85 \%$ (57/67) of $C$. difficile isolates. One strain was a non-toxigenic $C$. difficile $(1 \%, 1 / 67)$. Isolates belonging to ribotype 078 accounted for $91 \%$ (52/57) and ribotype 193 accounted for $9 \%(5 / 57)$ of binary toxin positive strains. The isolate of PCR-ribotype 035 was TcdA, TcdB and CDT negative.

C. difficile isolates originating from piglet litters belong predominantly to PCR-ribotypes 078 (30/34, 88\%) and 193 (4/34, 12\%) (Table 1). Seven different PCR-ribotypes were identified among sow isolates. PCR-ribotype 078 was the most frequently detected strain (22/33, 67\%). Other toxigenic PCR-ribotypes isolated that were positive for TcdA and TcdB but negative for binary toxin were 050 (4/33, 12\%), 014/020 (2/33, 6\%), 015 (2/33, 6\%), 029 (1/33, 3\%), and $193(1 / 33,3 \%)$. A non-toxigenic strain $035(1 / 33,3 \%)$ was also isolated from one sow.

Although PCR-ribotype 078 was the commonest PCR-ribotype found in both sows and piglet litters on all farms, and the only PCR-ribotype found in both sows and piglet litters in one farm (M1), the number of different PCR-ribotypes found on each farm varied greatly. The greatest variation of PCR-ribotypes was found on farm N1, where six different $C$. difficile PCR-ribotypes were isolated from sow samples (PCR-ribotypes 078, 015, 193, 050, 029 and 035) (Table 1). C. difficile isolated from sow samples from farm M2 were

Table 1

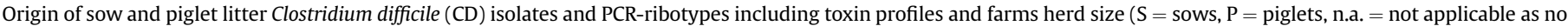
faecal samples received, serv. $=$ service, gest. $=$ gestation, far. $=$ farrowing, rec. $=$ received), *Isolation rates were excluded where the sample numbers were $\leq 2$.

\begin{tabular}{|c|c|c|c|c|c|c|c|c|c|c|c|}
\hline \multirow{2}{*}{$\begin{array}{l}\text { Farm (herd } \\
\text { size }[\mathrm{N}])\end{array}$} & \multirow[t]{2}{*}{ Pig's Age } & \multirow{2}{*}{$\begin{array}{l}\text { Rec. } \\
\text { samples (n) }\end{array}$} & \multirow{2}{*}{$\begin{array}{l}\text { CD } \\
\text { isolated } \\
\text { (n) }\end{array}$} & \multirow{2}{*}{$\begin{array}{l}\mathrm{CD} \\
\text { Isolation } \\
\text { Rate* }^{*}\end{array}$} & \multicolumn{7}{|c|}{ PCR-ribotypes (n) } \\
\hline & & & & & $\begin{array}{l}078(\mathrm{Tcd} A / \\
\mathrm{B}+, \mathrm{CDT}+)\end{array}$ & $\begin{array}{l}193(\mathrm{TcdA} / \\
\mathrm{B}+, \mathrm{CDT}+)\end{array}$ & $\begin{array}{l}050(\operatorname{Tcd} A / \\
\mathrm{B}+, \text { CDT- })\end{array}$ & $\begin{array}{l}014 / 020(\mathrm{TcdA} / \\
\mathrm{B}+, \mathrm{CDT}-)\end{array}$ & $\begin{array}{l}015(\mathrm{Tcd} A / \\
\mathrm{B}+, \text { CDT- })\end{array}$ & $\begin{array}{l}029(\operatorname{Tcd} A / \\
\mathrm{B}+, \text { CDT- })\end{array}$ & $\begin{array}{l}035(\mathrm{Tcd} A / \mathrm{B}- \\
\text {,CDT-) }\end{array}$ \\
\hline \multirow[t]{4}{*}{ N1 (90) } & S Serv. & 28 & 17 & $39 \%$ & 11 & 1 & 1 & & 2 & 1 & 1 \\
\hline & Gest. & 16 & 0 & & & & & & & & \\
\hline & Far. & 0 & n.a. & & & & & & & & \\
\hline & Total & 44 & 17 & & 11 & 1 & 1 & & 2 & 1 & 1 \\
\hline \multirow[t]{4}{*}{ N2 (300) } & S Serv. & 2 & 2 & $14 \%$ & 2 & & & & & & \\
\hline & Gest. & 12 & 0 & & & & & & & & \\
\hline & Far. & 0 & n.a. & & & & & & & & \\
\hline & Total & 14 & 2 & & 2 & & & & & & \\
\hline \multirow[t]{6}{*}{ M1 (700) } & S Serv. & 0 & n.a. & $*$ & & & & & & & \\
\hline & Gest. & 2 & 1 & & 1 & & & & & & \\
\hline & Far. & 0 & n.a. & & & & & & & & \\
\hline & $\begin{array}{l}\text { P } 0-7 \\
\text { days }\end{array}$ & 0 & n.a. & $75 \%$ & & & & & & & \\
\hline & $\begin{array}{l}14-28 \\
\text { days }\end{array}$ & 12 & 9 & & 9 & & & & & & \\
\hline & Total & 14 & 10 & & 10 & & & & & & \\
\hline \multirow[t]{4}{*}{ M2 (180) } & S Serv. & 42 & 10 & $23 \%$ & 6 & & 2 & 2 & & & \\
\hline & Gest. & 1 & 0 & & & & & & & & \\
\hline & Far. & 0 & n.a. & & & & & & & & \\
\hline & Total & 43 & 10 & & 6 & & 2 & 2 & & & \\
\hline \multirow[t]{6}{*}{ S1 (300) } & S Serv. & 0 & n.a. & $8 \%$ & & & & & & & \\
\hline & Gest. & 21 & 2 & & 1 & & 1 & & & & \\
\hline & Far. & 4 & 0 & & & & & & & & \\
\hline & $\begin{array}{l}\text { P } 0-7 \\
\text { days }\end{array}$ & 4 & 1 & $72 \%$ & 1 & & & & & & \\
\hline & $\begin{array}{l}14-28 \\
\text { days }\end{array}$ & 14 & 12 & & 12 & & & & & & \\
\hline & Total & 43 & 15 & & 14 & & 1 & & & & \\
\hline \multirow[t]{6}{*}{ S2 (650) } & S Serv. & 0 & n.a. & $4 \%$ & & & & & & & \\
\hline & Gest. & 25 & 0 & & & & & & & & \\
\hline & Far. & 3 & 1 & & 1 & & & & & & \\
\hline & $\begin{array}{l}\text { P 0-7 } \\
\text { days }\end{array}$ & 8 & 6 & S & 4 & 2 & & & & & \\
\hline & $\begin{array}{l}\text { 14-28 } \\
\text { days }\end{array}$ & 6 & 6 & & 4 & 2 & & & & & \\
\hline & Total & 42 & 13 & & 9 & 4 & & & & & \\
\hline Total & & 200 & 67 & & 52 & 5 & 4 & 2 & 2 & 1 & 1 \\
\hline
\end{tabular}


categorised as three different PCR-ribotypes (078, 050, 014/020). PCR-ribotype 193 was found only in four piglet litter $C$. difficile isolates on farm S2 and in one sow isolate from farm N2 (Table 1). A correlation between $C$. difficile PCR-ribotype diversity and farm herd size was not found.

\subsection{Potential transmission events}

A second sample was taken from 15 sows after $1-3$ months. Two sows (sow 1 from $\mathrm{N} 1$ and sow 2 from N2) were positive for C. difficile PCR-ribotype 078 in March, but only one of these (Sow 2) was positive at the second sampling and was colonised with a different PCR-ribotype 029 in June. Sows 3 and 4 (both from M2) were negative in March, but colonised with PCR-ribotype 078 in June (Table 2).

A mother-offspring connection between sow and piglet was established in eight cases, where faeces samples from sows and linked piglet litters samples were collected in June 2015. In these linked cases, $C$. difficile was found in all eight piglet litter faecal samples; PCR-ribotypes 078 (7 piglet litters) and 193 (1 piglet litter), but in only one of the sows (PCR-ribotype 078 during farrowing). Piglet litters of this sow also carried PCR-ribotype 078, were $0-7$ days old at time of sampling and originated from farm S2. This sow was the only sow colonised with $C$. difficile on farm S2. The isolation and characterisation of multiple PCR-ribotypes from sow or piglet litter samples was beyond the scope of this study.

\section{Discussion}

This is the first study to describe $C$. difficile isolation rates in sows and piglets on Irish pig farms from different geographical locations. The results of the study show that a $C$. difficile isolation rate as high as $77 \%$ was obtained from pooled piglet samples. As pooled piglet faeces samples were investigated, it cannot be determined if the $C$. difficile isolates recovered reflect $C$. difficile shedding of single piglets or whether more than one animal in each litter contributed to a positive result. Since the piglets in each litter pen live in close proximity to one another and presumably share a similar microflora of commensals and pathogens, then at a minimum at least one piglet from each litter with a positive pooled sample was shedding C. difficile at the time of sampling. The C. difficile isolation rate of $77 \%$ from piglet litter samples in this study is higher than rates reported by Norman et al. where C. difficile was isolated from only $50 \%$ of pooled samples from suckling piglets [21]. Keessen and colleagues isolated C. difficile from $36 \%$ of pooled faeces samples from nondiarrhoeal piglets and from $42.4 \%$ of faeces from diarrheal piglets, where 89 of the 139 faeces samples were pooled [22]. The isolation rate of $C$. difficile from piglets in other studies, where rectal swabs of individual animals were used to isolate $C$. difficile ranged from $26 \%$ to $73 \%$ across Europe $[5,12,23,24]$.

The results of this study indicate that within the piglet population isolation rates were higher in pooled samples from older piglets aged $14-28$ days ( $84 \%$ ) compared with $0-7$ day old piglets
(58\%). Whilst some studies report similar carriage rates for the $0-7$ day piglets [25] other faecal carriage reports indicate that the C. difficile isolation rate decreases with age, ranging from $56 \%$ in 7 day old piglets to $40 \%$ in 30 day old piglets and $7 \%$ in slaughter aged pigs which are approximately 6 months old $[13,26]$. Similarly Norman et al. reported a reduction in C. difficile rates from $50 \%$ in suckling piglets to $24 \%$ in lactating sows to only $3.9 \%(15 / 382)$ of pooled faeces samples from pigs of slaughter age [21].

The isolation rates of $C$. difficile in sows in this study (21\%) and the variation of carriage rate in accordance with gestational status of sows is consistent with findings of other reports. The $C$. difficile isolation rate from sows ranged from $0 \%$ to $50 \%$ in other studies and varied depending on gestational status [13,21,23]. The highest isolation in the present study was found during service of sows (40\%) and the lowest during gestation (4\%). In our study, the sows had no symptoms of diarrhoea at the time of sample collection. The variation in isolation rate and PCR-ribotype found in the fifteen sows which were sampled twice over the course of this study may suggest that sows undergo transient shedding, at least in some cases, rather than persistent colonisation, however a larger prospective study would be required to confirm this. It should also be noted that characterisation of a single colony type per faeces sample may have limited the diversity of $C$. difficile ribotypes isolated from these animals.

In this study, there was little variation in the $C$. difficile isolation rates from piglets (72-86\%) on three different farms. In contrast, other authors document a greater range in isolation rates in piglets which ranged from 10 to $100 \%$.The ranges observed in C. difficile isolation rates from sow samples on different farms in this study varied considerably with rates between 3 and 39\% documented.

The $C$. difficile isolates from piglets were predominantly PCRribotype 078 (88\%) which is not unexpected as this PCR-ribotype is commonly found in pigs in Europe and other parts of the world [5,9]. PCR-ribotype 193 was isolated from $12 \%$ of piglets and is closely related to PCR-ribotype 078. Studies have suggested that both of these PCR-ribotypes may have evolved from the same clonal lineage [27]. As described in human PCR-ribotypes in the hospital setting, $C$. difficile strains with the same PCR-ribotype may also persist on farms and may differentiate or evolve into subtypes [28]. The characterisation of only one $C$. difficile strain per pooled faecal sample could lead to an underestimation of the diversity of C. difficile strains reported in piglets. Although a greater diversity of PCR-ribotypes was isolated from the sow samples, PCR-ribotype 078 remained the dominant strain (67\%). In one farm alone, six different PCR-ribotypes were identified from sows $(078,015,193$, 050, 029 and 035). C. difficile PCR-ribotype 015 has been found in horses, whereas 029 is also known as a pathogen or commensal in pigs $[4,29]$ and PCR-ribotype 014/020 has been detected in dogs and cattle [29]. C. difficile can be found almost anywhere in the environment [30]. Further studies are required to identify environmental reservoirs and to investigate if environmental reservoirs are significant contributors to the spread of $C$. difficile 078 on pig farms in Ireland.

Table 2

Isolation of different Clostridium difficile (CD) PCR-ribotypes at different time points from faecal samples from four sows (n.a. = not applicable as no C. difficile isolated).

\begin{tabular}{|c|c|c|c|c|c|}
\hline & \multirow[t]{2}{*}{ Farm Location } & \multicolumn{2}{|l|}{$\begin{array}{l}\text { March } \\
2015\end{array}$} & \multicolumn{2}{|l|}{$\begin{array}{l}\text { June } \\
2015\end{array}$} \\
\hline & & CD isolated & PCR-ribotype & $\mathrm{CD}$ isolated & PCR-ribotype \\
\hline Sow 1 & N1 & yes & 078 & no & n.a. \\
\hline Sow 2 & $\mathrm{~N} 2$ & yes & 078 & yes & 029 \\
\hline Sow 3 & M2 & no & n.a. & yes & 078 \\
\hline Sow 4 & M2 & no & n.a. & yes & 078 \\
\hline
\end{tabular}


C. difficile may spread between sows and piglets. In this study, the same PCR-ribotype (078) was only found in one example of linked sow and its offspring. In all other linked cases where piglet litters and linked sows were sampled $(n=7)$ the $C$. difficile recovery data suggests no transmission link between sows and piglets.

Community-associated human CDI has increased in Europe over the last $10-20$ years with symptomatic patients presenting in the community in the absence of traditional risk factors [29]. Reasons for this increase remain unclear, but increased usage of antibiotics in the community, the global emergence of new epidemic strain types including PCR-ribotype 078, the growing reservoir of asymptomatic carriers and potential animal reservoirs are all possible explanations [29]. At present, PCR-ribotype 078 is the most common strain type found in humans in Ireland accounting for $20 \%$ of all CDI cases [31]. An emergence and increase of PCR-ribotype 078 has also been reported in animals worldwide [32]. Individual studies on comparative genomics suggest that human strains may have arisen from strains found in pigs $[3,10,33]$. Therefore, the potential for zoonotic spread of $C$. difficile between humans and pigs cannot be ruled out [10]. It is possible that zoonotic transmission of $C$. difficile is connected with the increase in communityassociated CDI [11].

This is the first study to document a high $C$. difficile isolation rate in Irish swine and provides important baseline data on $C$. difficile in neonatal pigs and sows. As observed elsewhere in Europe, $C$. difficile PCR-ribotype 078 was the most prevalent PCR-ribotype found in pigs. The predominance of PCR-ribotype 078, a strain increasingly implicated in community acquired CDI, suggests that the potential for zoonotic spread is particularly relevant in Ireland. Further studies are required to investigate if Irish porcine and human C. difficile PCR-ribotype 078 strains are genetically related.

\section{Conflicts of interest}

The authors report no conflicts of interest. The authors alone are responsible for the content and writing of the paper.

\section{References}

[1] F.C. Lessa, L.G. Winston, L.C. McDonald, Burden of Clostridium difficile infection in the United States, N. Engl. J. Med. 372 (24) (2015) 2369-2370.

[2] L.C. McDonald, M. Owings, D.B. Jernigan, Clostridium difficile infection in patients discharged from US short-stay hospitals, 1996-2003, Emerg. Infect. Dis. 12 (3) (2006) 409.

[3] D.N. Gerding, et al., Clostridium difficile binary toxin CDT: mechanism, epidemiology, and potential clinical importance, Gut Microbes 5 (1) (2014) 15-27.

[4] S. Janezic, et al., International Clostridium difficile animal strain collection and large diversity of animal associated strains, BMC Microbiol. 14 (2014) 173.

[5] J. Avbersek, et al., Diversity of Clostridium difficile in pigs and other animals in Slovenia, Anaerobe 15 (6) (2009) 252-255.

[6] M.G.J. Koene, et al., Clostridium difficile in Dutch animals: their presence, characteristics and similarities with human isolates, Clin. Microbiol. Infect. 18 (8) (2012) 778-784.

[7] C. Rodriguez, et al., Clostridium difficile in food and animals: a comprehensive review, Adv. Exp. Med. Biol. 932 (2016) 65-92.

[8] A. Goorhuis, et al., Clostridium difficile PCR ribotype 078: an emerging strain in humans and in pigs? J. Clin. Microbiol. 46 (3) (2008) 1157-1158.

[9] K. Keel, et al., Prevalence of PCR ribotypes among Clostridium difficile isolates from pigs, calves, and other species, J. Clin. Microbiol. 45 (6) (2007) 1963-1964.

[10] C.W. Knetsch, et al., Whole genome sequencing reveals potential spread of Clostridium difficile between humans and farm animals in The Netherlands, 2002 to 2011, Euro Surveill. 19 (45) (2014) 20954.

[11] J.G. Songer, M.A. Anderson, Clostridium difficile: an important pathogen of food animals, Anaerobe 12 (1) (2006) 1-4.

[12] A. Schneeberg, et al., Clostridium difficile genotypes in piglet populations in Germany, J. Clin. Microbiol. 51 (11) (2013) 3796-3803.

[13] J.S. Weese, et al., Longitudinal investigation of Clostridium difficile shedding in piglets, Anaerobe 16 (5) (2010) 501-504.

[14] Teagasc, Report: a Development Strategy for the Irish Pig Industry 2008-2015, January 2008. Dublin, Ireland.

[15] J.G. Songer, et al., Diagnostic notes: infection of neonatal swine with Clostridium difficile, Swine Health Prod. 8 (2000) 185-190.

[16] M.C. McElroy, et al., Typhlocolitis associated with Clostridium difficile ribotypes 078 and 110 in neonatal piglets from a commercial Irish pig herd, Ir. veterinary J. 69 (1) (2016) 10.

[17] M. Lister, et al., Comparison of culture based methods for the isolation of Clostridium difficile from stool samples in a research setting, Anaerobe 28 (2014) 226-229.

[18] L.G. Arroyo, et al., Use of a selective enrichment broth to recover Clostridium difficile from stool swabs stored under different conditions, J. Clin. Microbiol. 43 (10) (2005) 5341-5343.

[19] S. Persson, M. Torpdahl, K.E. Olsen, New multiplex PCR method for the detection of Clostridium difficile toxin $\mathrm{A}(\operatorname{tcdA})$ and toxin $\mathrm{B}(\operatorname{tcdB})$ and the binary toxin $(\mathrm{cdtA} / \mathrm{cdtB})$ genes applied to a Danish strain collection, Clin. Microbiol. Infect. 14 (11) (2008) 1057-1064.

[20] P. Bidet, et al., Development of a new PCR-ribotyping method for Clostridium difficile based on ribosomal RNA gene sequencing, FEMS Microbiol. Lett. 175 (2) (1999) 261-266.

[21] K. Norman, et al., Varied prevalence of Clostridium difficile in an integrated swine operation, Anaerobe 15 (6) (2009) 256-260.

[22] E. Keessen, et al., Evaluation of four different diagnostic tests to detect Clostridium difficile in piglets, J. Clin. Microbiol. 49 (5) (2011) 1816-1821.

[23] T. Norén, K. Johansson, M. Unemo, Clostridium difficile PCR ribotype 046 is common among neonatal pigs and humans in Sweden, Clin. Microbiol. Infect. 20 (1) (2014) 02-06.

[24] S. Alvarez-Perez, et al., Prevalence of Clostridium difficile in diarrhoeic and non-diarrhoeic piglets, Veterinary Microbiol. 137 (3-4) (2009) 302-305.

[25] D.R. Knight, M.M. Squire, T.V. Riley, Nationwide surveillance study of Clostridium difficile in Australian neonatal pigs shows high prevalence and heterogeneity of PCR ribotypes, Appl. Environ. Microbiol. 81 (1) (2015) 119-123.

[26] J.S. Weese, et al., Clostridium difficile and methicillin-resistant Staphylococcus aureus shedding by slaughter-age pigs, BMC Vet. Res. 7 (2011) 41.

[27] S. Janezic, M. Rupnik, Genomic diversity of Clostridium difficile strains, Res. Microbiol. 166 (4) (2015) 353-360.

[28] W. Fawley, et al., Use of highly discriminatory fingerprinting to analyze clusters of Clostridium difficile infection cases due to epidemic ribotype 027 strains, J. Clin. Microbiol. 46 (3) (2008) 954-960.

[29] M.P.M. Hensgens, et al., Clostridium difficile infection in the community: a zoonotic disease? Clin. Microbiol. Infect. 18 (7) (2012) 635-645.

[30] S. Janezic, et al., Clostridium difficile genotypes other than ribotype 078 that are prevalent among human, animal and environmental isolates, BMC Microbiol. 12 (2012) 48.

[31] K. Stein, et al., Epidemiology of Clostridium difficile infection in Ireland 2014 and 2015, Poster Presentation, Poster No. 1086, in: ECCMID, 2016 (Amsterdam, the Netherlands).

[32] A. Goorhuis, et al., Emergence of Clostridium difficile infection due to a new hypervirulent strain, polymerase chain reaction ribotype 078, Clin. Infect. Dis. 47 (9) (2008) 1162-1170.

[33] R. Stabler, et al., Comparative phylogenomics of Clostridium difficile reveals clade specificity and microevolution of hypervirulent strains, J. Bacteriol. 188 (20) (2006) 7297-7305. 